40 
Contributors to this volume:

Alessio Ageno

Jean-Pierre Antoine

Sandro Caparrini

Frans A. Cerulus

Sidney D. Drell

David Ritz Finkelstein

Laszlo Grenacs

Donal Hurley

Giuseppe La Rocca

Siegmund Levarie

Bernd Lindemann

Giulio Maltese

Wolfgang K.H. Panofsky

Orietta Pedemonte

Patricia Radelet-de Grave

Luigi A. Radicati di Brozolo

Michael Vandyck

Piero Villaggio

Kim Williams 


\section{Two Cultures}

Essays in Honour of David Speiser

Kim Williams

Editor

Birkhäuser Verlag

Basel • Boston • Berlin 
Editor:

Kim Williams

Kim Williams Books

Via Cavour, 8

10123 Torino

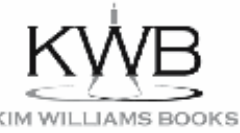

Italy

e-mail:kwilliams@kimwilliamsbooks.com

2000 Mathematics Subject Classification 00B30

A CIP catalogue record for this book is available from the Library of Congress, Washington D.C., USA

Bibliographic information published by Die Deutsche Bibliothek

Die Deutsche Bibliothek lists this publication in the Deutsche Nationalbibliografie; detailed bibliographic data is available in the Internet at $<$ http://dnb.ddb.de $>$.

ISBN 3-7643-7186-2 Birkhäuser Verlag, Basel - Boston - Berlin

This work is subject to copyright. All rights are reserved, whether the whole or part of the material is concerned, specifically the rights of translation, reprinting, re-use of illustrations, recitation, broadcasting, reproduction on microfilms or in other ways, and storage in data banks. For any kind of use permission of the copyright owner must be obtained.

(C) 2006 Birkhäuser Verlag, P.O. Box 133, CH-4010 Basel, Switzerland

Part of Springer Science+Business Media

Cover illustrations:

Giovanni Bellini, Sacra Conversazione, Pinacoteca di Brera, Milan

Root diagram of SU(3) and its lattice $\mathrm{g}^{\mathrm{c}}$. Diagram by Jean-Pierre Antoine.

Translation from French to English for this volume by Sylvie Duvernoy.

Translation from Italian to English for this volume by Kim Williams.

Printed on acid-free paper produced from chlorine-free pulp. TCF $\infty$

Printed in Germany

ISBN-10: 3-7643-7186-2

e-ISBN: 3-7643-7540-X

ISBN-13: 978-3-763-7186-9

$987654321 \quad$ www.birkhauser.ch 


\section{Contents}

\section{Introduction}

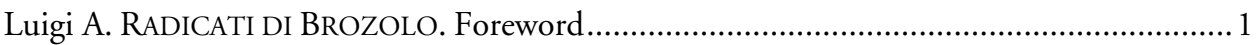

Kim WILLIAMS. Reflections on Interdisciplinarianism....................................................

\section{The Sciences}

Jean-Pierre ANTOINE. David Speiser's Group Theory:

From Stiefel's Crystallographic Approach to Kac-Moody Algebras ...................................... 13

David Ritz FInKELSTEIN. Whither Quantum Theory?....................................................25

Laszlo GRENACS. The Direct Determination of the Induced Pseudoscalar Current (and about the slow metamorphosis of an institution) ...........................................................39

Giuseppe LA RocCA and Luigi RADICATI Di BROZOLO. In Praise of Asymmetry ................45

Donal HURLEY and Michael VANDYCK. An Observation

about the Huygens Clock Problem...............................................................................59

\section{The History of Science}

Frans A. CERULUS. Daniel Bernoulli and Leonhard Euler on the Jetski...............................73

Giulio Maltese. On the Changing Fortune of the Newtonian Tradition in Mechanics ....97

Patricia RADELET-DE GRAVE. Studies of Magnetism

in the Correspondence of Daniel Bernoulli

Piero VILlagGio. On Enriques's Foundations of Mechanics

Sandro CAPARRINI. On the Common Origin of Some of the Works on the Geometrical Interpretation of Complex Numbers.

\section{The Arts}

Siegmund LeVARIE. Architecture and Music.

Bernd Lindemann. An Unusual Sacra Conversazione by Giovanni Bellini.

Alessio Ageno and Orietta Pedemonte. Ancient Astrological and Musical Analogies in the Renaissance: Palladio's Villa Rotunda and a Geometric Construction by Leonardo167

\section{Nuclear Arms}

Sidney D. DreLl. The Gravest Danger: Nuclear Weapons and their Proliferation 181

Wolfgang K.H. PANOFSKY. Nuclear Arms Control

\section{Reference}

Bibliography of Works by David Speiser. 


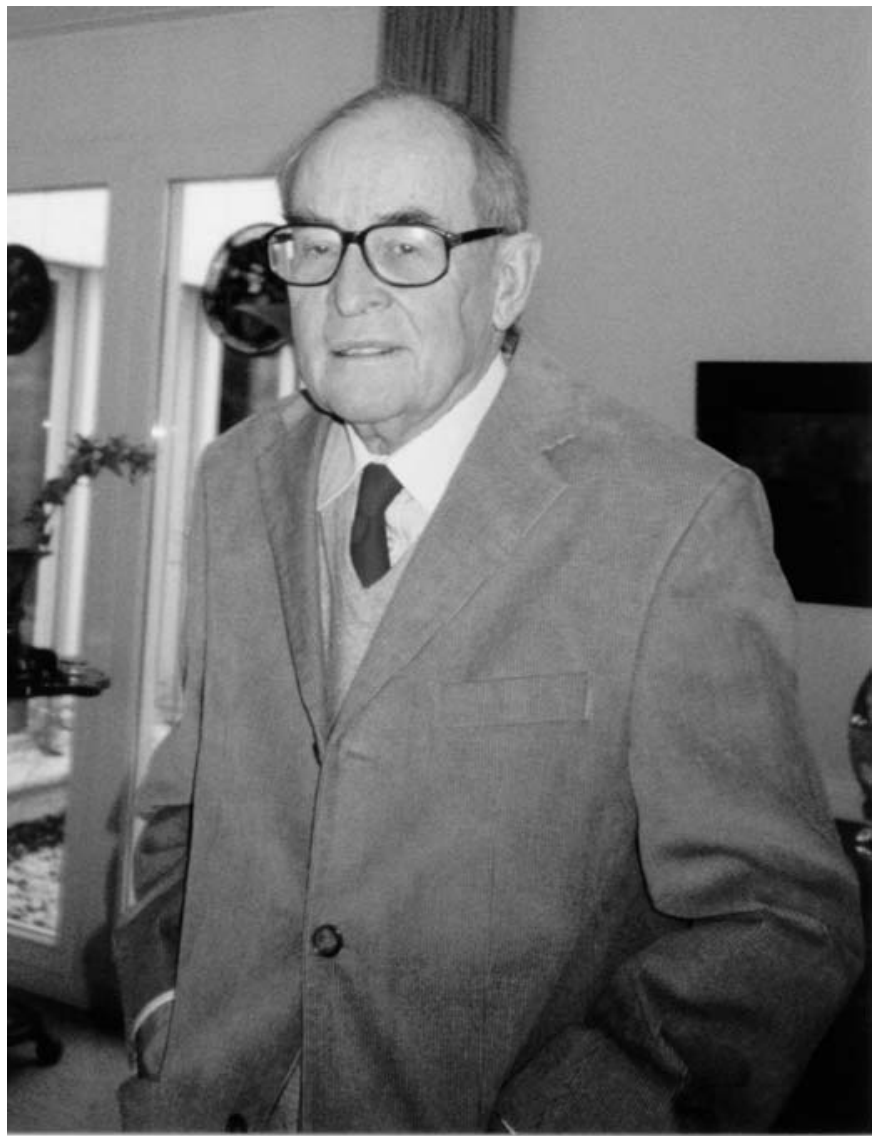

David Speiser, 2005 


\section{FOREWORD}

This book is dedicated with love, gratitude and admiration to Professor David Speiser by a group of his friends on the occasion of his eightieth birthday.

Let me say a few words about our dear friend David. He grew up in the highly civilised atmosphere of Basel, a state unto a state, un des lieux saints de notre civilization, as Lucien Fevre wrote echoing, one hundred years later, Jakob Burckhardt who had written "small states exist so that there may be some spot on earth where the largest possible proportion of the members of the state are citizens in the fullest sense of the word." Beside having been born in such a blessed place, David has had the additional privilege of growing up in the intellectual and cosmopolitan milieu of a family where artists, scientist, musicians were frequent visitors. Moreover David's uncle, Andreas Speiser, was an eminent mathematician who besides an influential book, Die Theorie der Gruppen von endlicher Ordung, wrote a delightful essay, Die Matematishe Denkweise, which introduced his gifted nephew to the mysterious relations between mathematics and the arts, a leit-motiv in all David's thinking.

I said in the beginning that this Festshrift is a token of our admiration for the breadth of David's interests, which range from science to history to the arts. It is enough to look at the impressive list of his publications: a paper on the hexagonal symmetry in a Mycenean jewel; several papers and seminar talks on the irreducible representations of the group SU(3) needed to accommodate all elementary particles known at that time (1960-61) and on the importance of this group in the weak interaction transitions; papers on general relativity and quaternionic quantum mechanics, etc., etc. Then comes the impressive list of his papers on the history of science.

Personally I owe to David all the little I know on the history of physics, which I learned from his series of inspiring lectures at the Scuola Normale Superiore on Galileo, Newton, Huygens, Maupertuis, etc. His monumental work on the Bernoulli papers is his monumentum aere perennius. Though I admire bronze monuments, I confess my preference for silver and gold: of this stuff is made his book on Petrus Peregrinus; his articles on the symmetries of the Leaning Tower and the Battistero in Pisa have been to me a real joy. However, what I have enjoyed most has always been talking to David, often disagreeing with him but always impressed by his wide-ranging knowledge and the brilliance of his opinions. We've been talking for more than forty years and still do it, unfortunately now only on the phone. Thank you David for our friendship.

I said, David, you've been lucky to have been born in Basel and to have grown up in the stimulating atmosphere of your family: however il meglio mi scordavo. You have found the most charming, accomplished and, if I may add, patient wife, and that, in my opinion, may not be the least of your accomplishments. May you and Ruth enjoy many, many years of fruitful life in your buon ritiro of Arlesheim and may the Lord bless you.

Happy birthday, David

Luigi A. Radicati di Brozolo 